\title{
Cross interactions on interfacial compound formation of solder bumps and metallization layers during reflow
}

\author{
T.L. Shao, T.S. Chen, Y.M. Huang, and Chih Chen ${ }^{\text {a) }}$ \\ National Chiao Tung University, Department of Material Science \& Engineering, \\ Hsin-chu 300 Taiwan, Republic of China
}

(Received 10 May 2004; accepted 20 September 2004)

\begin{abstract}
While the dimension of solder bumps keeps shrinking to meet higher performance requirements, the formation of interfacial compounds may be affected more profoundly by the other side of metallization layer due to a smaller bump height. In this study, cross interactions on the formation of intermetallic compounds (IMCs) were investigated in eutectic $\mathrm{SnPb}, \mathrm{SnAg} 3.5, \mathrm{SnAg} 3.8 \mathrm{Cu} 0.7$, and $\mathrm{SnSb} 5$ solders jointed to $\mathrm{Cu} / \mathrm{Cr}-\mathrm{Cu} / \mathrm{Ti}$ on the chip side and $\mathrm{Au} / \mathrm{Ni}$ metallization on the substrate side. It is found that the $\mathrm{Cu}$ atoms on the chip side diffused to the substrate side to form $\left(\mathrm{Cu}_{x,} \mathrm{Ni}_{1-x}\right)_{6} \mathrm{Sn}_{5}$ or $\left(\mathrm{Ni}_{y}, \mathrm{Cu}_{1-y}\right)_{3} \mathrm{Sn}_{4}$ for the four solders during the reflow for joining flip chip packages. For the $\mathrm{SnPb}$ solder, Au atoms were observed on the chip side after the reflow, yet few $\mathrm{Ni}$ atoms were detected on the chip side. In addition, for $\mathrm{SnAg} 3.5$ and $\mathrm{SnSn} 5$ solders, the $\mathrm{Ni}$ atoms on the substrate side migrated to the chip side during the reflow to change binary $\mathrm{Cu}_{6} \mathrm{Sn}_{5}$ into ternary $\left(\mathrm{Cu}_{x}, \mathrm{Ni}_{1-x}\right){ }_{6} \mathrm{Sn}_{5} \mathrm{IMCs}$, in which the $\mathrm{Ni}$ weighed approximately $21 \%$. Furthermore, it is intriguing that no $\mathrm{Ni}$ atoms were detected on the chip side of the $\mathrm{SnAg} 3.8 \mathrm{Cu} 0.7$ joint. The possible driving forces responsible for the diffusion of $\mathrm{Au}, \mathrm{Ni}$, and $\mathrm{Cu}$ atoms are discussed in this paper.
\end{abstract}

\section{INTRODUCTION}

Flip chip technology has become one of the most important packaging technologies for microelectronic packaging. ${ }^{1,2}$ One of its advantages is that a large number of tiny solder bumps can be fabricated into an area array on a chip as input/output (I/O) interconnections. The interconnections establish when the solder reacts with the under bump metallization (UBM) on the chip side and the pad metallization on the substrate side to form intermetallic compounds (IMCs). To meet the performance requirement, the size of the bumps must shrink continuously. The reliability and joint strength of flip chip package is highly related with the IMC formation of flip chip joints. Therefore, metallurgical reactions between the solder and metallization layers become an important reliability issue, since the volume ratio of the IMCs increases while the dimension of the solder bumps decreases. Therefore, the influence of the IMCs on the solder joint reliability becomes more prominent than before. $^{3}$

In addition, with increasing environmental concerns, the microelectronics industry is paying more attention to

\footnotetext{
a) Address all correspondence to this author.

e-mail: chih@cc.nctu.edu.tw

DOI: $10.1557 / J M R .2004 .0478$
}

lead-free solder alternatives. ${ }^{4,5}$ Among the alternatives, eutectic SnAg3.5 and SnAg3.8Cu0.7 solder appear to be two of most promising candidates for replacing eutectic $\mathrm{SnPb}$ solder. In addition, $\mathrm{SnSb} 5$ solder could be used in high-temperature application due to its high liquidus temperature of $240{ }^{\circ} \mathrm{C}$. Due to higher content of $\mathrm{Sn}$ in most of the $\mathrm{Pb}$-free solders, the amount of IMCs formed is larger than that in the eutectic $\mathrm{SnPb}$ solder. Therefore, in most of $\mathrm{Pb}$-free solders, the rapid consumption rate of UBM and fast formation rate of IMCs are other reliability concerns.

The metallurgical reactions between solders and the metallization layers have been investigated extensively, in which $\mathrm{Sn}$ reacts with $\mathrm{Cu}$ or Ni metallization layers to form IMCs. ${ }^{6-8}$ Spalling of IMCs were reported when thin film $\mathrm{Cu} \mathrm{UBM}$ reacted with eutectic $\mathrm{SnPb}$ and $\mathrm{Pb}$-free solders. ${ }^{9,10}$ A method has been developed to prevent the spalling of IMCs by the opposite interfacial reaction on the substrate side. ${ }^{11}$ Furthermore, Tu et al. reported that $\mathrm{Au}$ layer on the substrate-side affected the spalling of IMCs on the chip-side across a solder joint. ${ }^{9}$ Liu et al. found that $\mathrm{Cu}$ atoms diffused to the other side of the $\mathrm{SnAg}$ solder to form ternary $\mathrm{Cu}-\mathrm{Ni}-\mathrm{Sn}$ IMCs during reflow in a $\mathrm{Cu}-\mathrm{SnAg}-\mathrm{Ni}$ sandwich structure. ${ }^{12}$ When the dimension of the solder bumps shrinks, the bump height also decreases accordingly. Interfacial reactions during solid state aging have been studied. ${ }^{13,14}$ Thus these cross 
interactions on formation of interfacial IMCs become more pronounced than before. However, little research has been done on the cross interaction behaviors. From the scientific point of view, it is of interest to study the cross interactions between the Cu-based UBM in the chip side and the Ni-based pad metallization on the substrate side since $\mathrm{Cu}$ and $\mathrm{Ni}$ are the most common materials used in the UBM and in the pad metallization, respectively. In this paper, we use a systematic method to investigate the cross interactions in eutectic $\mathrm{SnPb}, \mathrm{SnAg} 3.5$, SnAg3.8Cu0.7, and SnSb5 solders. Three types of samples, including dumped dies, bumped substrates, and flip chip packages, were fabricated and examined to verify the cross interactions during reflow. We found that $\mathrm{Ni}$ atoms diffused to the chip side to form $\mathrm{Cu}-\mathrm{Ni}-\mathrm{Sn}$ ternary IMC after the joining of the flip chip packages for $\mathrm{SnPb}, \mathrm{SnAg} 3.5$, and $\mathrm{SnSb5}$ solders, while no Ni atoms were detected in the chip side of SnAg3.8Cu0.7 flip chip packages. Possible mechanisms responsible for the different diffusion behaviors are discussed.

\section{EXPERIMENTAL}

Three sets of samples were prepared in this study and they are illustrated schematically in Figs. 1(a)-1(c). The first ones were bumped dies, in which the UBM consisted of $0.7 \mu \mathrm{m} \mathrm{Cu} / 0.3 \mu \mathrm{m} \mathrm{Cr}-\mathrm{Cu} / 0.1 \mu \mathrm{m}$ Ti UBM. The chip size is $9.5 \times 6.0 \mathrm{~mm}$ with $105 \mu \mathrm{m}$ UBM diameter. Four kinds of solders were adopted: eutectic $\mathrm{SnPb}$, SnAg3.5, SnAg3.8Cu0.7, and SnSb5. Solder pastes were printed and deposited on the UBM pad of the wafers. Then the wafers were reflowed in a nitrogen atmosphere oven with the peak temperatures of $210,250,250$, and $280{ }^{\circ} \mathrm{C}$ for the $\mathrm{SnPb}, \mathrm{SnAg} 3.5, \mathrm{SnAg} 3.8 \mathrm{Cu} 0.7$, and $\mathrm{SnSb} 5$ solders, respectively. They remained above the liquidus for approximately $60 \mathrm{~s}$. Figure 1(a) shows the schematic diagram of the samples after the reflow.

The second set of samples included bumped substrates. The metallization pad of the bismaleimide triazine (BT) substrates were $0.025 \mu \mathrm{m} \mathrm{Au} / 5 \mu \mathrm{m}$ $\mathrm{Ni}-\mathrm{P} / 20 \mu \mathrm{m} \mathrm{Cu}$. Again, the solder pastes were printed and deposited on the metallization surface of the BT substrates. The substrates were also reflowed at the peak temperature of $210,250,250$, and $280{ }^{\circ} \mathrm{C}$ for the $\mathrm{SnPb}$, $\mathrm{SnAg} 3.5, \mathrm{SnAg} 3.8 \mathrm{Cu} 0.7$, and $\mathrm{SnSb5}$ solders, respectively. They remained above the liquidus temperature for approximately $60 \mathrm{~s}$. Figure 1(b) depicts the schematic of the bumped substrate after reflow.

The third set of samples included typical flip chip packages with the same UBM and pad metallization as those in the bumped dies and substrates. They were fabricated by joining the bumped dies to the BT substrates. Firstly, bumped dies were prepared, and then solder pastes were printed on the metallization surface through a metal stencil. Afterward, the bumped dies were flipped

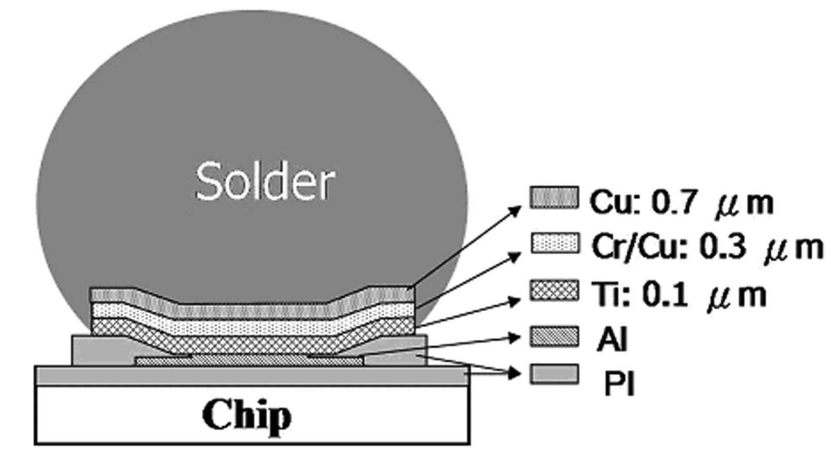

(a)

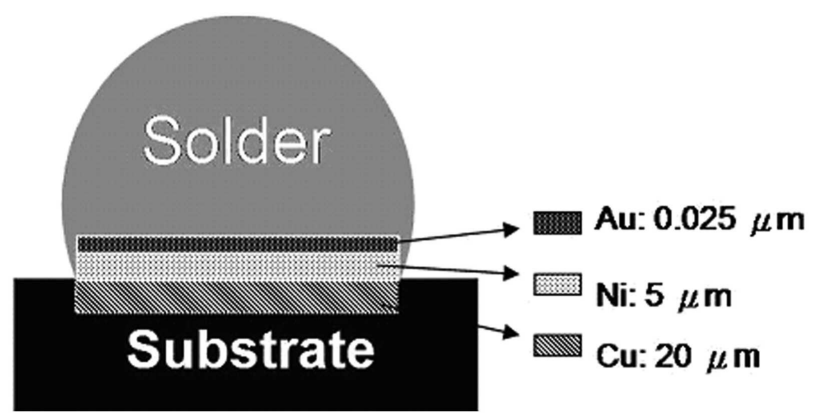

(b)

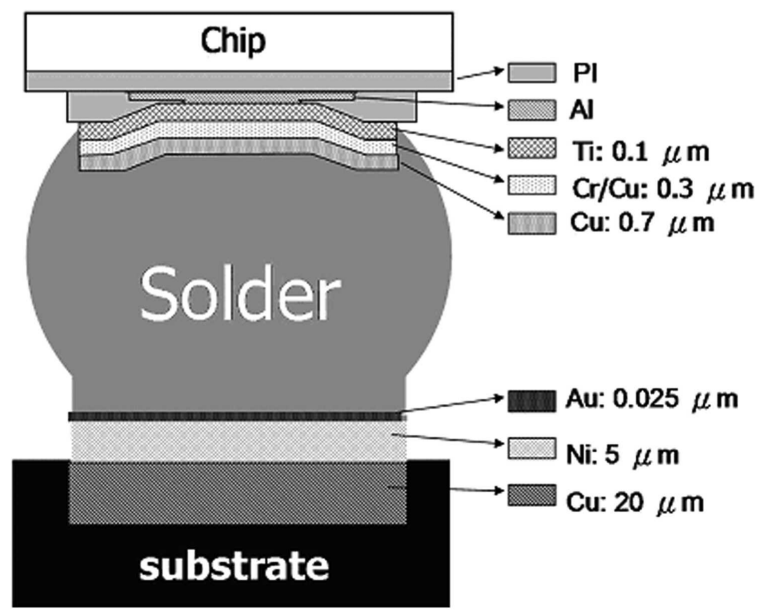

(c)

FIG. 1. Schematic illustration of the different sets of test samples used in this study: (a) bumped die, (b) bumped substrate, and (c) flip chip package.

and joined to the BT substrates. Then the flip chip packages were reflowed in a nitrogen atmosphere oven with the peak temperatures of $210,250,250$, and $280{ }^{\circ} \mathrm{C}$ for the $\mathrm{SnPb}, \mathrm{SnAg} 3.5, \mathrm{SnAg} 3.8 \mathrm{Cu} 0.7$, and SnSb5 solders, respectively. They remained above the melting or liquidus temperatures for approximately $60 \mathrm{~s}$. This reflow will be referred to as the "second reflow" in the following discussion. The flip chip joints formed after the second reflow, when the cross interactions may take place. Finally, the flip chip packages were underfilled.

To examine the interfacial IMCs more clearly, the 
three sets of samples were observed from both crosssectional views and plan views. During preparation, cross-sectional scanning electron microscope (SEM) samples were polished laterally approximately to the center of the bumps, while the plan-view SEM samples were polished either from the substrate side or chip side to the middle of the solder bumps, and they were then selectively etched by the solution of nitric acid: acetic acid: glycerol at the ratio of 1:1:1, which etches Sn and almost does not attack IMCs of Sn. The microstructures and the compositions of IMCs were examined by a JEOL (Tokyo, Japan) 6500 field emission SEM and energy dispersive spectroscopy (EDS), respectively. The resolution of the composition analysis was $\pm 0.5 \%$, and the samples were coated with Pt film prior to SEM observation.

By comparing the microstructures and compositions between the bumped die and the flip chip package of the same solder, the cross interactions between the IMCs on the chip side and the $\mathrm{Au} / \mathrm{Ni}$ metallization on the substrates side can be examined. How the $\mathrm{Cu} / \mathrm{Cr}-\mathrm{Cu} / \mathrm{Ti}$ UBM on the chip side affects the formation of IMCs on the substrate side can be verified from the comparison of the microstructures between the bumped substrate and the flip chip package of the same solder. The composition labeled in this paper is in weight percent unless specified.

\section{RESULTS}

\section{A. Eutectic SnPb solder}

To provide the IMC microstructures without the cross interactions, the interfacial microstructures for the $\mathrm{SnPb}$ bumped die and the $\mathrm{SnPb}$ bumped substrate were examined from both cross-sectional and plan-view secondaryelectron SEM images. For the bumped die, after the first reflow, the $\mathrm{Cu}_{6} \mathrm{Sn}_{5}$ IMCs were formed due to the interfacial reaction between eutectic $\mathrm{SnPb}$ solder and the $\mathrm{Cu}$ UBM, as illustrated in Fig. 2(a). Figure 2(b) shows the plan-view SEM image of the $\mathrm{Cu}_{6} \mathrm{Sn}_{5}$ IMCs after the selective etching of the $\mathrm{SnPb}$ solder, in which the scallop-like $\mathrm{Cu}_{6} \mathrm{Sn}_{5}$ IMCs attach to the UBM on the chip side. These results are consistent with the earlier findings by $\mathrm{Tu}^{3,6}$ On the contrary, IMCs of $\mathrm{Ni}_{3} \mathrm{Sn}_{4}$ were detected on the interface of eutectic $\mathrm{SnPb}$ solder and Ni pad metallization of the BT substrate for the bumped substrate. Figures 2(c) and 2(d) depict the cross-sectional and planview SEM images for the interfacial microstructure of the bumped substrate, respectively. Needle-shaped and block-shaped $\mathrm{Ni}_{3} \mathrm{Sn}_{4}$ IMCs formed at the interface, and $\mathrm{Au}$ was detected in the IMCs. The dark layer between the $\mathrm{Ni}_{3} \mathrm{Sn}_{4}$ and the electroless $\mathrm{Ni}$ layer is crystalline $\mathrm{Ni}_{3} \mathrm{P} .{ }^{15}$

Cross interactions on formation of interfacial IMCs were found when a bumped die was reflowed to join the substrate. The $\mathrm{Cu}$ atoms on the UBM of the chip side diffused to the substrate side, and the $\mathrm{Au}$ and $\mathrm{Ni}$ atoms diffused to the chip side to form IMCs during the second reflow. Figure 3(a) shows the cross-sectional SEM image of the interfacial IMCs on the chip side. Surprisingly, few ternary IMCs of $(\mathrm{Cu}, \mathrm{Ni})_{6} \mathrm{Sn}_{5}$ were found on the UBM interface of the chip side, as indicated by the arrows in Fig. 3. The rest of the IMCs were determined to be $\mathrm{Cu}_{6} \mathrm{Sn}_{5}$. The IMCs were also examined from the planview SEM image after the removal of the $\mathrm{SnPb}$ solder, as
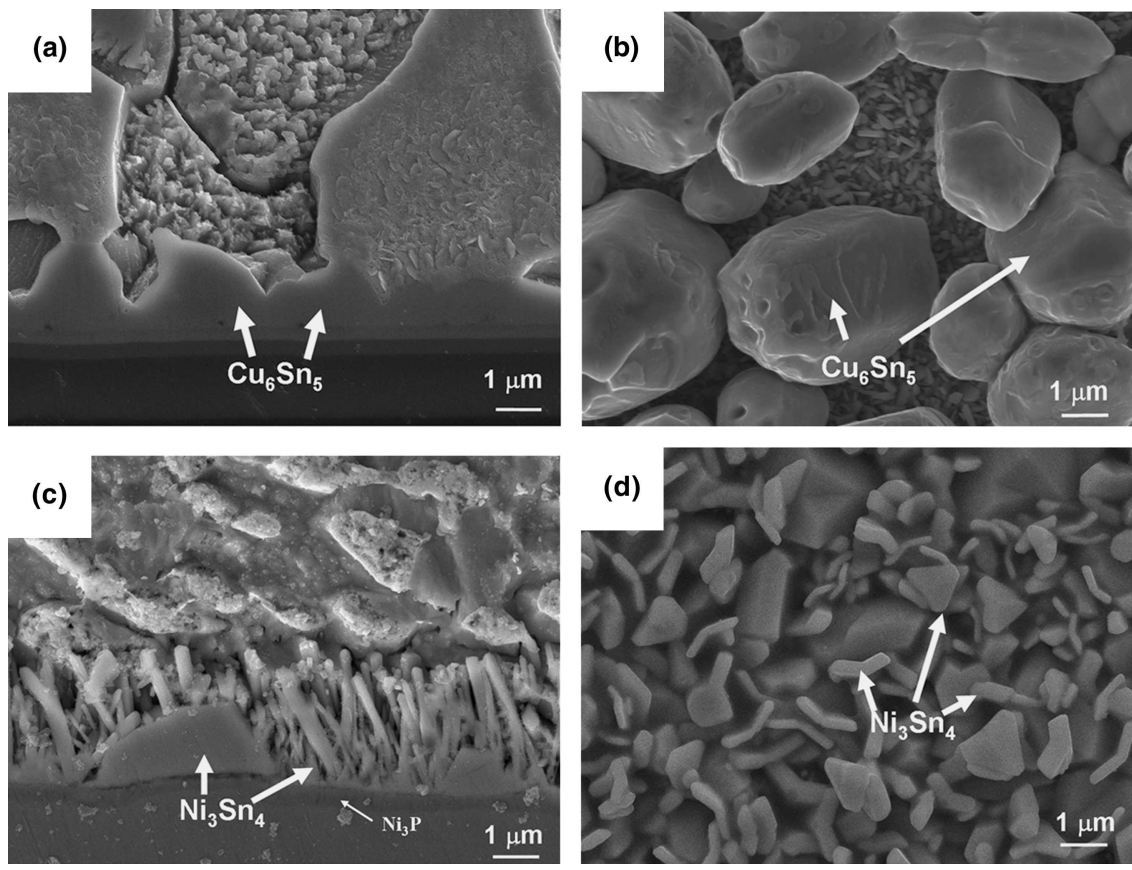

FIG. 2. SEM images of the interfacial microstructure of the eutectic SnPb solder bump after the first reflow: (a) cross-sectional view of the bumped die, (b) plan view of the bumped die, (c) cross-sectional view of the bumped substrate, and (d) plan view of the bumped substrate. 

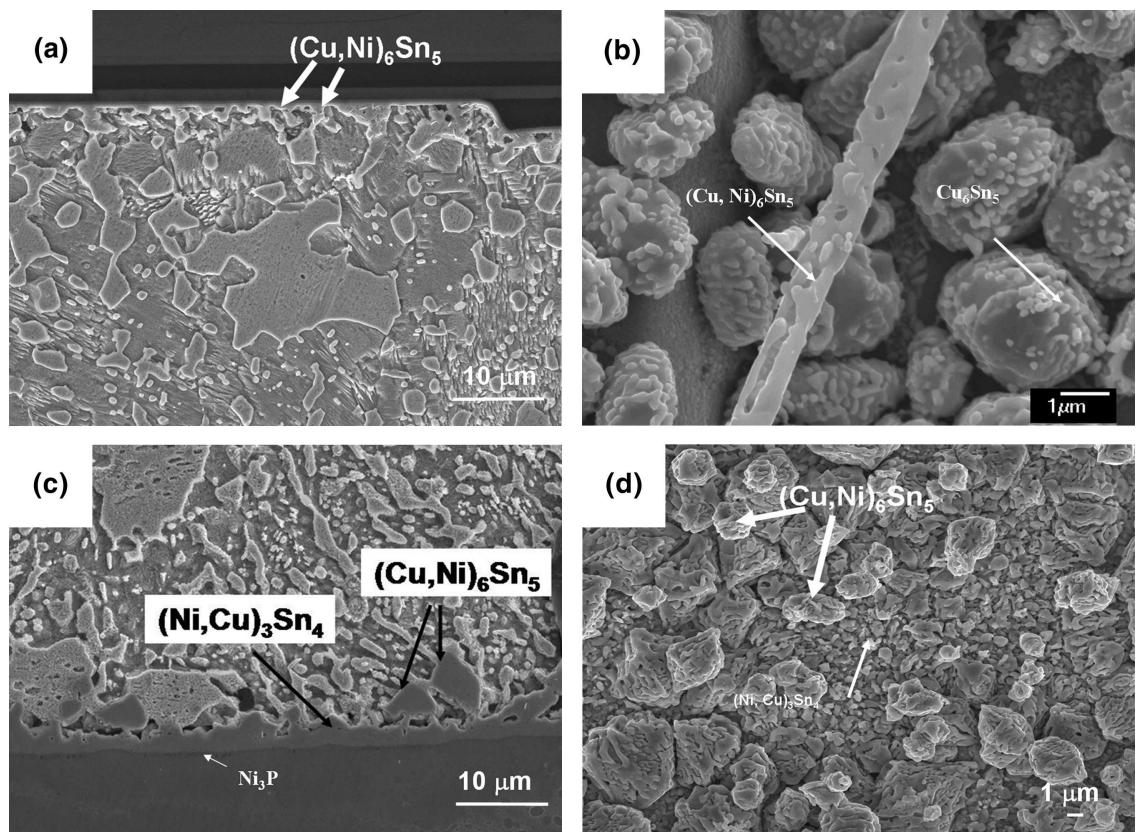

FIG. 3. SEM images of the interfacial microstructure of the eutectic SnPb solder bump in flip chip package after the second reflow: (a) cross-sectional view of the chip side, (b) plan view of the chip side, (c) cross-sectional view of the substrate side, and (d) plan view of the substrate side.

shown in Fig. 3(b). Numerous tiny particles were found coated on the surface of the $\mathrm{Cu}_{6} \mathrm{Sn}_{5}$ IMCs. EDS results show that the tiny particles contained $4 \%$ Au. They might be $\mathrm{AuSn}_{4}$ IMCs, in which the Au atoms came from the metallization layer in the substrate during the second reflow. $\mathrm{Tu}$ et al. also observed similar tiny particles coated on the surface of $\mathrm{Cu}_{6} \mathrm{Sn}_{5}$ IMCs when eutectic $\mathrm{SnPb}$ solder was reflowed on a $\mathrm{Cr} / \mathrm{Cu} / \mathrm{Au} \mathrm{UBM} .{ }^{10}$ Furthermore, $\mathrm{Au}$ atoms dissolve very fast in $\mathrm{SnPb}$ solder. ${ }^{16}$ Although the Au concentration in our $\mathrm{SnPb}$ case after the second reflow was less than the solubility ( $0.3 \mathrm{wt} . \%)$, the $\mathrm{Au}$ could be depleted from the solid solution when the $\mathrm{AuSn}_{4}$ particles on $\mathrm{Cu}_{6} \mathrm{Sn}_{5}$ IMCs has a lower chemical potential than that of $\mathrm{Au}$ or $\mathrm{AuSn}_{4}$ dissolved in the eutectic $\mathrm{SnPb}$. Therefore, it is possible that the Au atoms (or the An-Sn IMCs) in the substrate side might diffuse to the chip side and precipitate out on the surface of the $\mathrm{Cu}_{6} \mathrm{Sn}_{5}$ IMCs during the second reflow. A needle-type IMC was observed, as indicated by the arrow in Fig. 3(b). It was identified to be $\left(\mathrm{Cu}_{x}, \mathrm{Ni}_{1-x}\right){ }_{6} \mathrm{Sn}_{5}$ with few percent of $\mathrm{Ni}$ dissolved into $\mathrm{Cu}_{6} \mathrm{Sn}_{5}$ IMCs. Since there are no $\mathrm{Ni}$ atoms in the UBM of the chip side and in the solder, the $\mathrm{Ni}$ atoms may diffuse from the substrate side during the second reflow.

On the other hand, the IMC morphology on the substrate side became quite different from that IMCs on the chip side after the first reflow, as seen in Fig. 3(c). The interfacial IMCs of $\left(\mathrm{Cu}_{x} \mathrm{Ni}_{1-x}\right)_{6} \mathrm{Sn}_{5}$ and $\left(\mathrm{Ni}_{y}, \mathrm{Cu}_{1-y}\right)_{3} \mathrm{Sn}_{4}$ were observed, in which the $\mathrm{Cu}$ atoms were from the metallization layer on the chip side. Figure 3(d) shows the SEM image of the plan-view $\left(\mathrm{Cu}_{x}, \mathrm{Ni}_{1-\mathrm{x}}\right)_{6} \mathrm{Sn}_{5}$ and
$\left(\mathrm{Ni}_{y}, \mathrm{Cu}_{1-y}\right)_{3} \mathrm{Sn}_{4}$ IMCs, in which the $\mathrm{Ni}$ weighs $14 \%$ in $\left(\mathrm{Cu}_{x}, \mathrm{Ni}_{1-x}\right)_{6} \mathrm{Sn}_{5}$ and $\mathrm{Cu}$ weighs $13 \%$ in $\left(\mathrm{Cu}_{x} \mathrm{Ni}_{1-x}\right)_{6} \mathrm{Sn}_{5}$. Compared with that in Fig. 2(d), the morphology of the IMCs in Fig. 3(d) changes from needle-shaped or blockshaped to rock-shaped.

\section{B. SnAg3.5 solder}

For the $\mathrm{SnAg} 3.5$ bumped die, $\mathrm{Cu}_{6} \mathrm{Sn}_{5}$ IMCs formed in the interface of the solder and the UBM on the chip side, as seen in Fig. 4(a). Several $\mathrm{Cu}_{6} \mathrm{Sn}_{5}$ IMCs spalled from the UBM, as indicated in the figure. Since the thickness of the $\mathrm{Cu}$ UBM was about $0.7 \mu \mathrm{m}$, spalling of IMCs might occur after the first reflow. ${ }^{10}$ Figure 4(b) depicts the SEM plan-view image for the chip side, in which $\mathrm{Cr}-\mathrm{Cu}-\mathrm{Sn}$ layer was detected. It is speculated that the spalled or partially spalled $\mathrm{Cu}_{6} \mathrm{Sn}_{5}$ IMCs were removed during the selective etching of the $\mathrm{SnAg}$ solder. For the $\mathrm{SnAg} 3.5$ bumped substrate, the $\mathrm{Ni}_{3} \mathrm{Sn}_{4}$ IMCs were found on the interface between $\mathrm{SnAg}$ solder and Ni pad metallization of the BT substrate after the first reflow. Figure 4(c) shows the cross-sectional SEM image of the interfacial microstructure of the bumped substrate sample. Two types of morphologies were observed for the $\mathrm{Ni}_{3} \mathrm{Sn}_{4}$ IMCs: needle-shaped and block-shaped, which are also visualized in the plan-view SEM image for the IMCs on the substrate side, as seen in Fig. 4(d).

After the joining of the SnAg3.5 flip chip package, the cross-sectional microstructure on the chip side is shown in Fig. 5(a). Most of the $\mathrm{Cu}-\mathrm{Sn}$ IMCs on the chip side spalled after the second reflow for the solder, while some $\mathrm{Ag}_{3}$ Sn IMCs were observed, as indicated by the arrows 

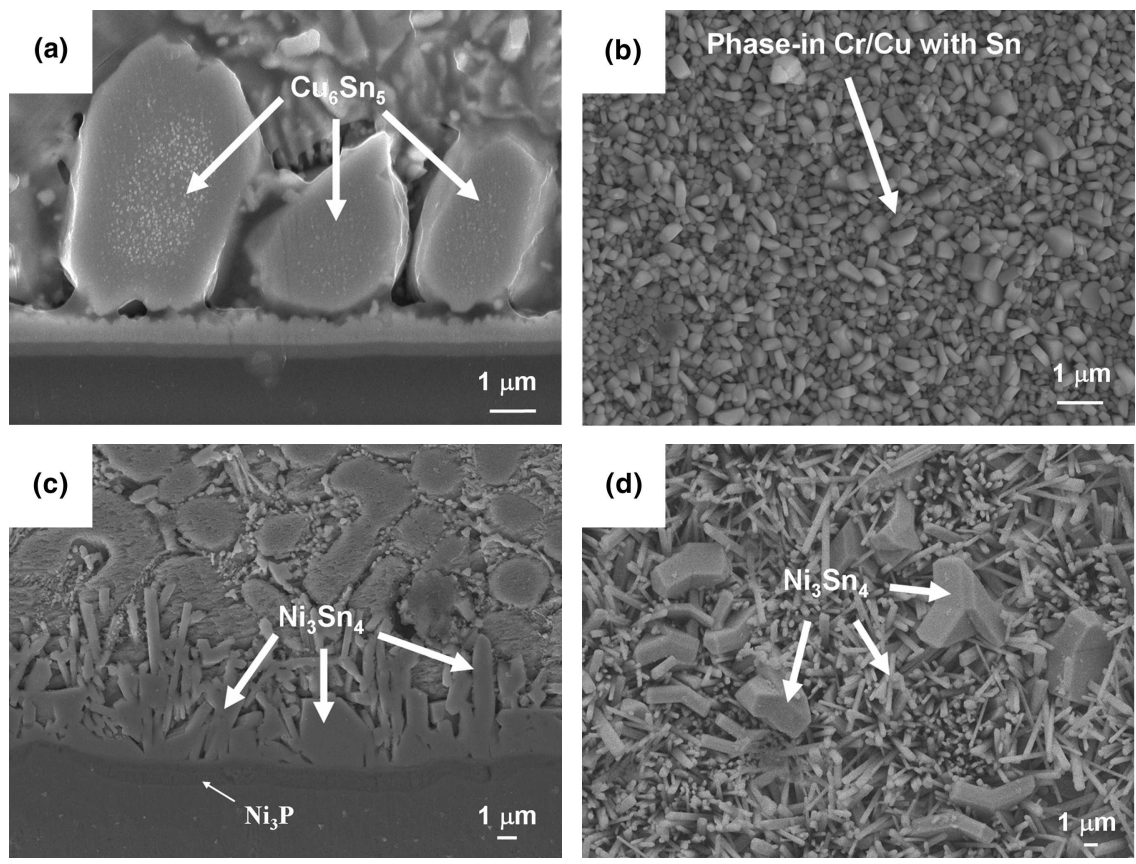

FIG. 4. SEM images of the interfacial microstructure of the eutectic SnAg3.5 solder bump after the first reflow: (a) cross-sectional view of the bumped die, (b) plan view of the bumped die, (c) cross-sectional view of the bumped substrate, and (d) plan view of the bumped substrate.
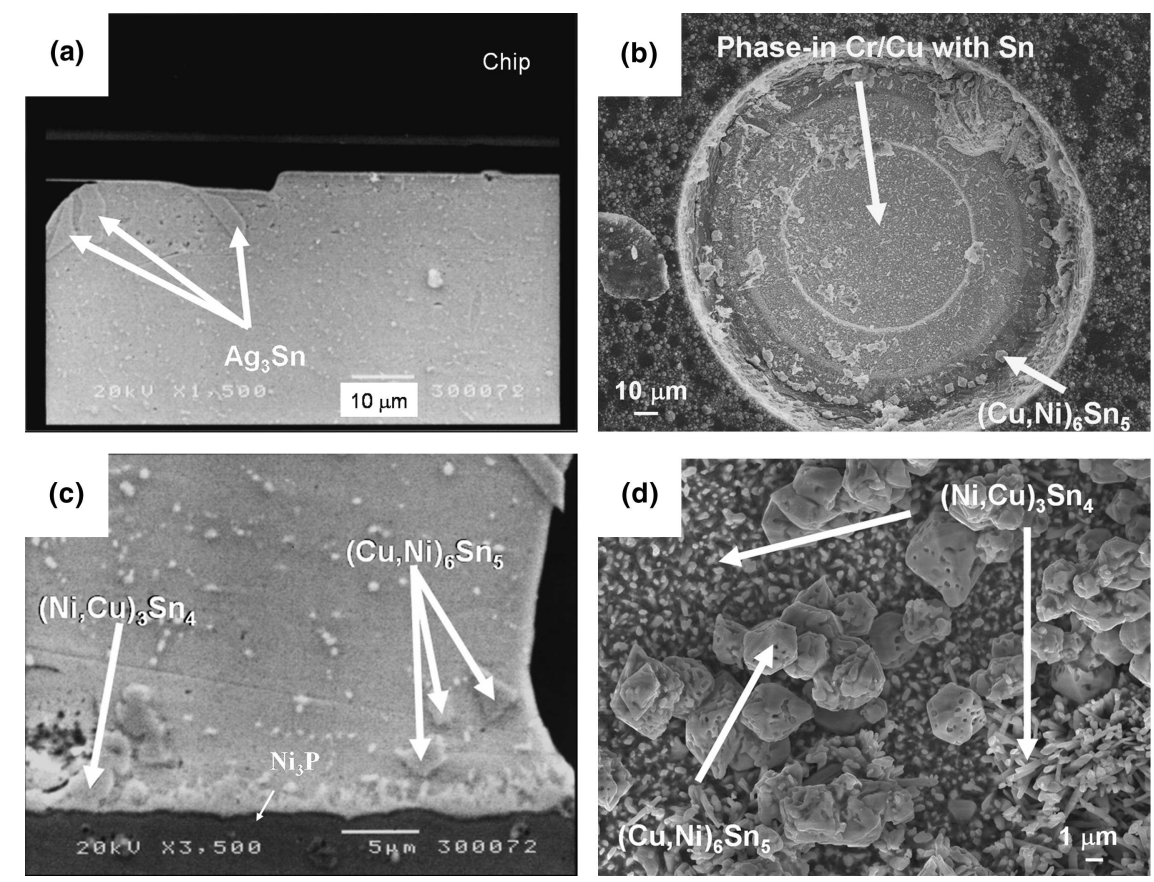

FIG. 5. SEM images of the interfacial microstructure of the eutectic SnAg3.5 solder bump in flip-chip package after the second reflow: (a) cross-sectional view of the chip side, (b) plan view of the chip side, (c) cross-sectional view of the substrate side, and (d) plan view of the substrate side.

in the figure. Occasionally, IMCs of $\left(\mathrm{Cu}_{x}, \mathrm{Ni}_{1-x}\right)_{6} \mathrm{Sn}_{5}$ were found on the periphery of the contact opening of the chip side, as seen in the plan-view SEM image in Fig. 5(b). They contained $21 \%$ of Ni. On the substrate side, Fig. 5(c) shows that the ternary $\left(\mathrm{Cu}_{x}, \mathrm{Ni}_{1-x}\right){ }_{6} \mathrm{Sn}_{5}$ IMCs locate inside the solder near the pad metallization, and they contain about $32 \%$ of $\mathrm{Cu}$ atoms. However, $\left(\mathrm{Ni}_{y}, \mathrm{Cu}_{1-y}\right)_{3} \mathrm{Sn}_{4}$ IMCs formed on the interface of $\mathrm{SnAg}$ solder and pad metallization of the substrate, in which about $10 \%$ of $\mathrm{Cu}$ atoms dissolved in the IMCs.

Therefore, comparing the IMC compositions of the bumped die/substrate and the flip chip package shows 
that the cross-interfacial reactions exist in the SnAg3.5 solder. It is speculated that $\mathrm{Cu}$ atoms on the chip side move to the substrate side during the second reflow, and $\mathrm{Ni}$ atoms on the substrate side diffuse to $\mathrm{Cu}_{6} \mathrm{Sn}_{5}$ IMCs on the chip side to form $\left(\mathrm{Cu}_{x}, \mathrm{Ni}_{1-x}\right)_{6} \mathrm{Sn}_{5}$ IMCs.

\section{SnSb5 solder}

The interface microstructures for the bumped die and for the bumped substrate were examined after the first reflow without cross interactions. IMCs of $\mathrm{Cu}_{6} \mathrm{Sn}_{5}$ were observed on the interface of UBM and solder on the chip side, as shown in Fig. 6(a). Occasionally, IMCs of $\mathrm{Sn}_{3} \mathrm{Sb}_{2}$ were found near the interface, as indicated by one of the arrows in the figure. The plan-view SEM image of the IMCs is seen in Fig. 6(b). The shape of the $\mathrm{Cu}_{6} \mathrm{Sn}_{5}$ IMCs is scallop-like. No $\mathrm{Au}$ atoms were detected in IMCs, although there were tiny particles coated on the surface of the IMCs. On the other hand, IMCs of $\mathrm{Ni}_{3} \mathrm{Sn}_{4}$ formed on the interface between $\mathrm{SnSb} 5$ solder and $\mathrm{Ni}$ metallization of the BT substrate after the first reflow. Figures 6(c) and 6(b) show the cross-sectional and planview SEM images for the IMC microstructures of the bumped substrate, respectively. Similar to $\mathrm{SnAg} 3.5$ solder, both needle-shaped and block-shaped $\mathrm{Ni}_{3} \mathrm{Sn}_{4}$ were observed. No obvious $\mathrm{Ni}_{3} \mathrm{P}$ layer was observed between the $\mathrm{Ni}_{3} \mathrm{Sn}_{4}$ and the electroless $\mathrm{Ni}$ layer, which may be due to less $\mathrm{Ni}_{3} \mathrm{Sn}_{4}$ IMCs formation.

Cross interactions also occur in the SnSb5 solder after its second reflow for joining the flip chip package. For the flip chip package, ternary IMCs of $\left(\mathrm{Cu}_{x} \mathrm{Ni}_{1-x}\right)_{6} \mathrm{Sn}_{5}$ formed in the interface of SnSb5 solder and the UBM on the chip side, as illustrated in Fig. 7(a), in which the $\mathrm{SnSb} 5$ solder was selectively etched for clear observation of the IMCs. The shape of the $\left(\mathrm{Cu}_{x}, \mathrm{Ni}_{1-x}\right)_{6} \mathrm{Sn}_{5}$ IMCs is scallop-like, as seen in the plan-view SEM image in Fig. 7(b). The concentration of $\mathrm{Ni}$ atoms in the ternary IMCs was measured to be $23 \%$. On the substrate side, both ternary $\left(\mathrm{Cu}_{x}, \mathrm{Ni}_{1-x}\right)_{6} \mathrm{Sn}_{5}$ and $\left(\mathrm{Ni}_{y}, \mathrm{Cu}_{1-y}\right)_{3} \mathrm{Sn}_{4}$ IMCs formed near the interface of the $\mathrm{SnSb} 5$ solder and the pad metallization after the second reflow, as seen in Fig. 7(c). Figure 7(d) shows the plan-view SEM image, in which the two IMCs are labeled. The shape of the $\left(\mathrm{Ni}_{y}, \mathrm{Cu}_{1-y}\right)_{3} \mathrm{Sn}_{4}$ IMCs is layered-like and their $\mathrm{Cu}$ content weighs $9 \%$. The ternary $\left(\mathrm{Cu}_{x}, \mathrm{Ni}_{1-x}\right)_{6} \mathrm{Sn}_{5}$ IMCs are column-like, and they contain $35 \%$ of $\mathrm{Cu}$. Again, Ni atoms migrated from the substrate side to the chip side, and they reacted with $\mathrm{Cu}_{6} \mathrm{Sn}_{5}$ to form $\left(\mathrm{Cu}_{x} \mathrm{Ni}_{1-x}\right)_{6} \mathrm{Sn}_{5}$ IMCs. Furthermore, $\mathrm{Cu}$ atoms diffused from the chip side to the substrate side to form $\left(\mathrm{Cu}_{x}, \mathrm{Ni}_{1-x}\right)_{6} \mathrm{Sn}_{5}$ and $\left(\mathrm{Ni}_{y}, \mathrm{Cu}_{1-y}\right)_{3} \mathrm{Sn}_{4}$ IMCs after the second reflow.

\section{Eutectic SnAg3.8Cu0.7 solder}

For the $\mathrm{SnAg} 3.8 \mathrm{Cu} 0.7$ bumped die, IMCs of $\mathrm{Cu}_{6} \mathrm{Sn}_{5}$ formed in the interface of the UBM and the $\mathrm{SnAg} 3.8 \mathrm{Cu} 0.7$ solder, as shown in the cross-sectional SEM image in Fig. 8(a). Some of the $\mathrm{Cu}_{6} \mathrm{Sn}_{5}$ IMCs spalled after the first reflow. Figure 8(b) illustrates the plan-view SEM image for the contact opening on the chip side. Some $\mathrm{Cu}_{6} \mathrm{Sn}_{5}$ IMCs were left after the selective etching of the solder. It is speculated that some of the spalled $\mathrm{Cu}_{6} \mathrm{Sn}_{5}$ IMCs were removed during the etching
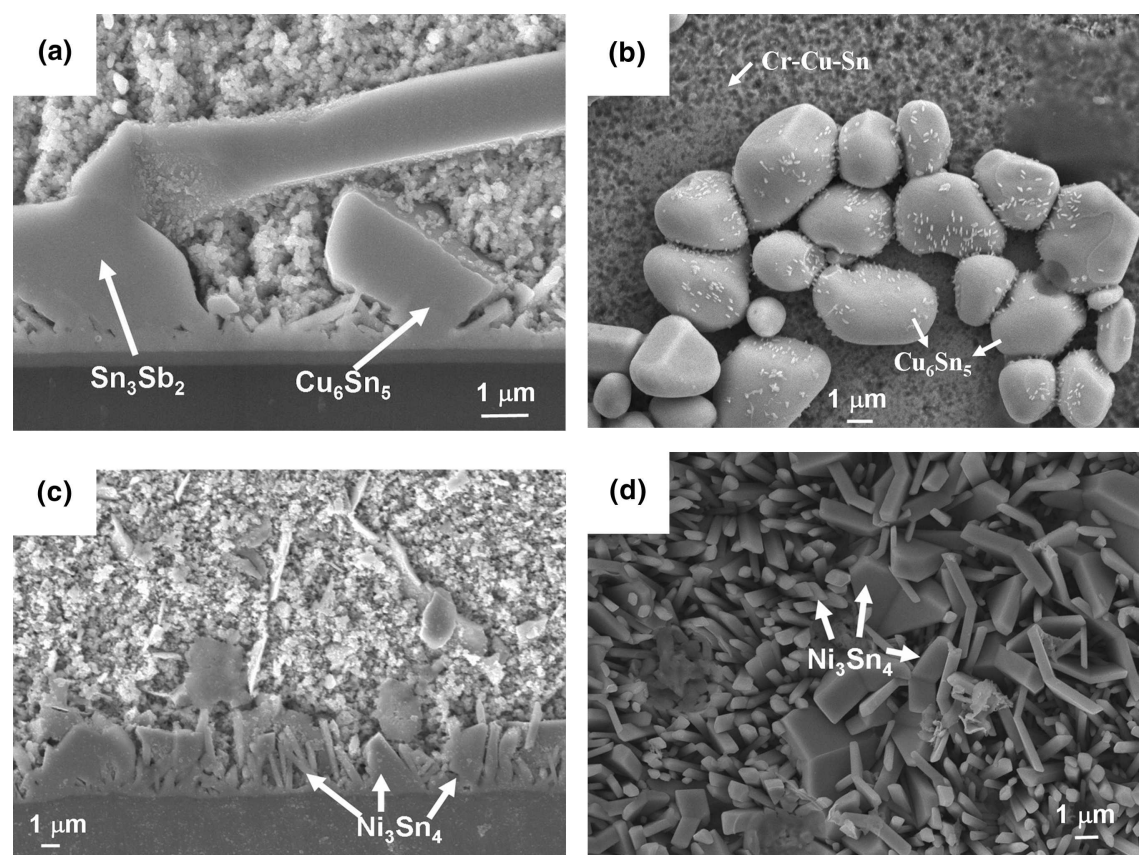

FIG. 6. SEM images of the interfacial microstructure of the SnSb5 solder bump after the first reflow: (a) cross-sectional view of the bumped die, (b) plan view of the bumped die, (c) cross-sectional view of the bumped substrate, and (d) plan view of the bumped substrate. 

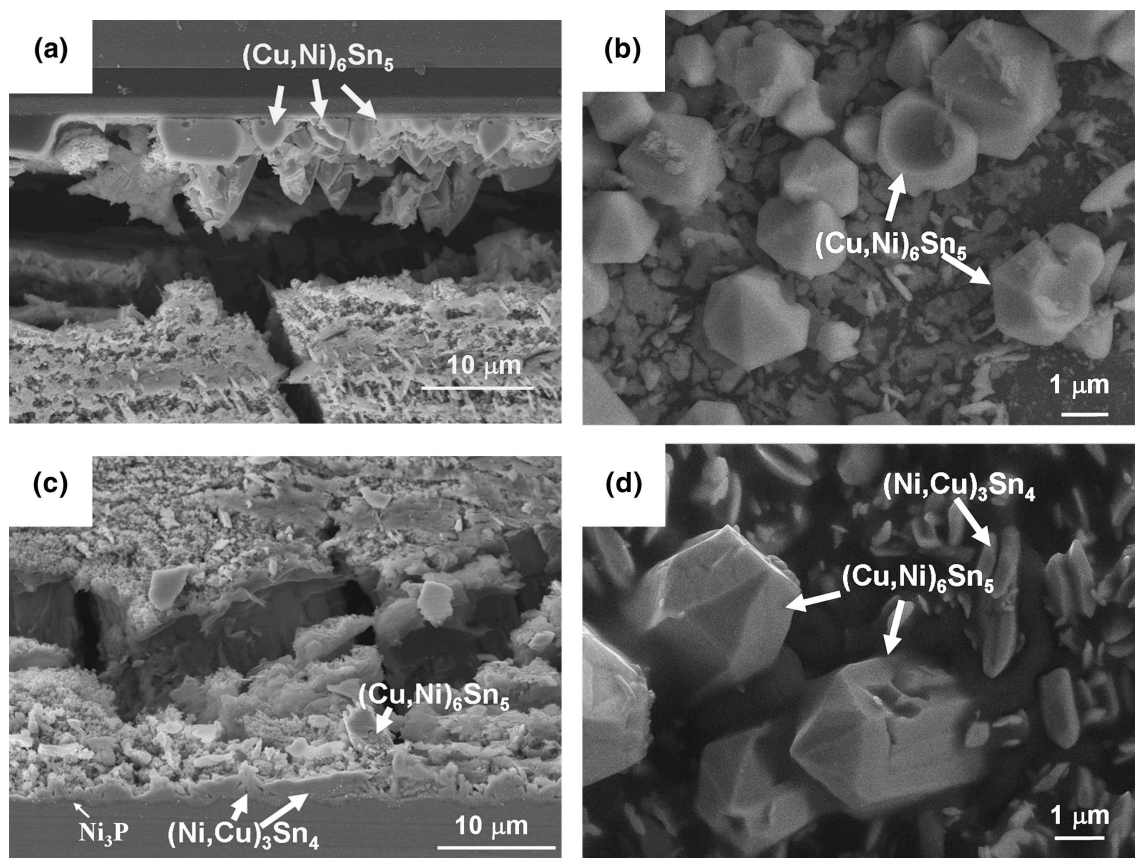

FIG. 7. SEM images of the interfacial microstructure of the SnSb5 solder bump in flip-chip package after the second reflow: (a) cross-sectional view of the chip side, (b) plan view of the chip side, (c) cross-sectional view of the substrate side, and (d) plan view of the substrate side.
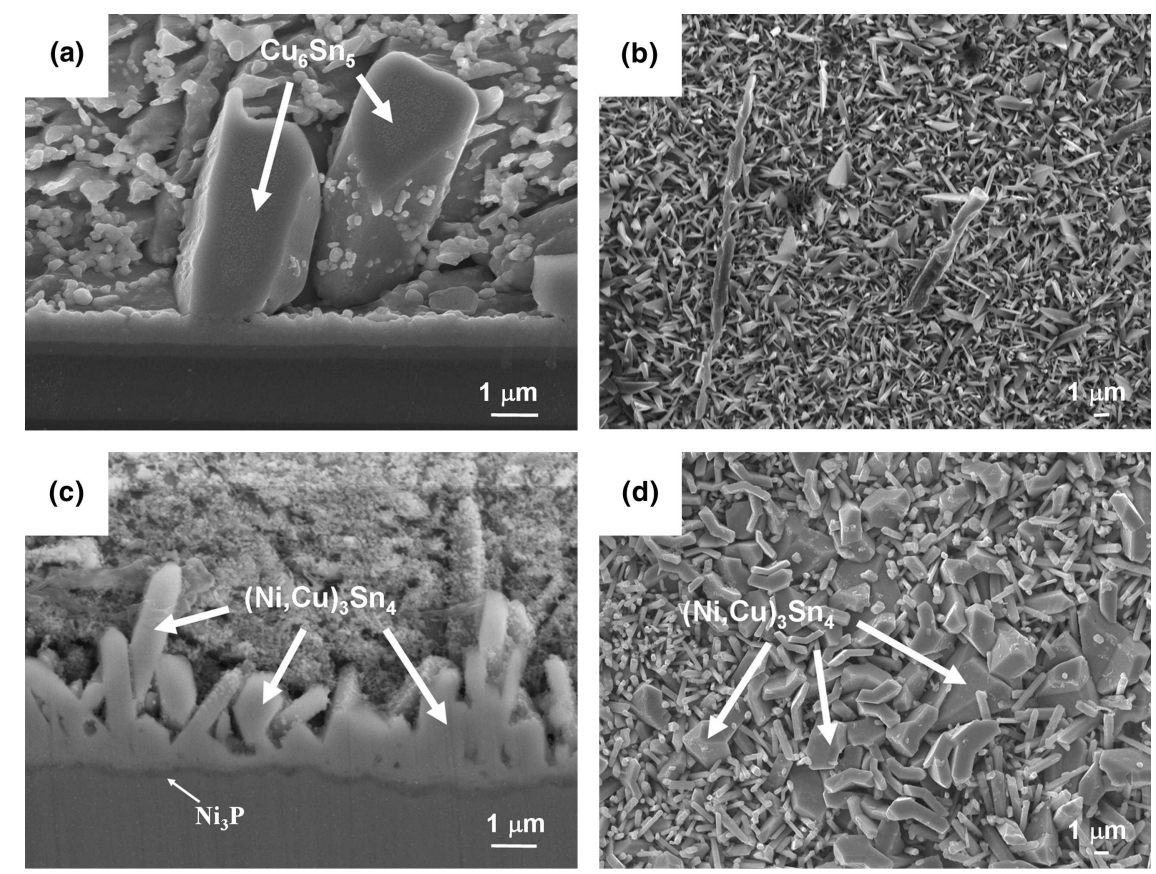

FIG. 8. SEM images of the interfacial microstructure of the eutectic SnAg3.8Cu0.7 solder bump after the first reflow: (a) cross-sectional view of the bumped die, (b) plan view of the bumped die, (c) cross-sectional view of the bumped substrate, and (d) plan view of the bumped substrate.

of the solder. Therefore, a $\mathrm{Cr}-\mathrm{Cu}-\mathrm{Sn}$ layer was observed for the rest of the area. For the bumped substrate, IMCs of $\left(\mathrm{Ni}_{y}, \mathrm{Cu}_{1-y}\right)_{3} \mathrm{Sn}_{4}$ formed on the interface of the $\mathrm{SnAg} 3.8 \mathrm{Cu} 0.7$ solder and Ni metallization layer, as seen in Fig. 8(c). The $\mathrm{Cu}$ atoms in the IMCs come from the solder itself, and they weigh approximately $17 \%$. Their morphology is visualized in Fig. 8(d), which shows the plan-view SEM image after the removal of the $\mathrm{SnAgCu}$ solder. Although they contain $\mathrm{Cu}$, their morphology is similar to that of the $\mathrm{Ni}_{3} \mathrm{Sn}_{4}$ IMCs formed when $\mathrm{SnAg} 3.5$ and $\mathrm{SnSb} 5$ solders reacted with the metallization layer on the substrate side.

Surprisingly, Ni atoms were not detectable on the chip side of the SnAgCu flip chip package. The IMCs on the 
chip side remained to be binary $\mathrm{Cu}_{6} \mathrm{Sn}_{5}$. The crosssectional and plan views of the interfacial microstructures are shown in Figs. 9(a) and 9(b), respectively. Sporadic $\mathrm{Cu}_{6} \mathrm{Sn}_{5}$ IMCs are observed in the interface of the UBM on the chip side. Spalling becomes more serious after the second reflow. On the substrate side, both $(\mathrm{Cu}, \mathrm{Ni})_{6} \mathrm{Sn}_{5}$ and $\left(\mathrm{Ni}_{y}, \mathrm{Cu}_{1-y}\right)_{3} \mathrm{Sn}_{4}$ IMCs formed after the joining of the flip chip package. Compared with the microstructure of the bumped substrate in Figs. 9(c) and 9(d), the formation of $(\mathrm{Cu}, \mathrm{Ni})_{6} \mathrm{Sn}_{5}$ IMCs may be attributed to the cross interactions. Since more $\mathrm{Cu}$ atoms are needed to form $(\mathrm{Cu}, \mathrm{Ni})_{6} \mathrm{Sn}_{5} \mathrm{IMCs}$, the $\mathrm{Cu}$ atoms in the $(\mathrm{Cu}, \mathrm{Ni})_{6} \mathrm{Sn}_{5}$ IMCs come mainly from the chip side.

\section{DISCUSSION}

To verify theoretically whether the $\mathrm{Ni}$ and $\mathrm{Cu}$ atoms are able to diffuse farther than the joint height of the flip chip package during the reflow, we assume that the diffusivity of $\mathrm{Cu}$ and $\mathrm{Ni}$ atoms in the liquid state during reflow is about $10^{-5} \mathrm{~cm}^{2} / \mathrm{s} .{ }^{17}$ Since they remain above the melting points of the above four solders for approximately $60 \mathrm{~s}$, the diffusion distance is estimated to be approximately $245 \mu \mathrm{m}$, which is longer than the joint height of $90 \mu \mathrm{m}$. Therefore, it is possible for the above cross interactions to happen during the reflow process.

The evolution of the IMCs and their compositions for the above four solders are summarized in Table I. Table I(a) displays the IMCs formed on the substrate side and their compositions for the bumped die and the flipchip package. The evolution of the IMCs is clearly seen in the tables. Copper atoms diffused to the substrate side in the four solders after joining the flip chip packages. It is speculated that the $\mathrm{Cu}$ atoms in the UBM on the chip side dissolved into the $\mathrm{SnPb}$ solder during the first reflow. The solder may be saturated with $\mathrm{Cu}$ atoms. In addition, $\mathrm{Cu}_{6} \mathrm{Sn}_{5}$ IMCs may form at the surface of the bumps. During the second reflow, the dissolved $\mathrm{Cu}$ as well as the $\mathrm{Cu}$ from $\mathrm{Cu}_{6} \mathrm{Sn}_{5}$ IMCs may immediately participate in the interfacial reaction between the $\mathrm{SnPb}$ solder and $\mathrm{Ni}$ metallization. Moreover, more $\mathrm{Cu}$ atoms in the metallization layer on the chip side may diffuse to the substrate side during the second reflow. The $\mathrm{Cu}$ atoms are present on the substrate side in the form of $\left(\mathrm{Cu}_{x}, \mathrm{Ni}_{1-x}\right)_{6} \mathrm{Sn}_{5}$ and $\left(\mathrm{Ni}_{y}, \mathrm{Cu}_{1-y}\right)_{3} \mathrm{Sn}_{4}$. Kao et al. reported that the ternary IMCs possess lower free energy than the binary $\mathrm{Cu}_{6} \mathrm{Sn}_{5}$ and $\mathrm{Ni}_{3} \mathrm{Sn}_{4}$ IMCs. ${ }^{18}$ This potential gradient may provide the driving force for the $\mathrm{Cu}$ and $\mathrm{Ni}$ atoms to diffuse to form the ternary IMCs. Liu et al. found a $\mathrm{Cu}$ concentration gradient across the solder due to lower $\mathrm{Cu}$ solubility limit at the $\mathrm{Ni}$ end in a sandwich structure of $\mathrm{Cu}-\mathrm{SnAg}-\mathrm{Ni} .{ }^{11}$ Therefore, it is inferred that this concentration gradient would accelerate the dissolution of $\mathrm{Cu}$ atoms on the chip side. Once the $\mathrm{Cu}$ metallization layer is consumed, the spalling of IMCs occurs due to high interfacial energy between the IMCs and the $\mathrm{Cr}-\mathrm{Cu}$ layer, as seen in Figs. 5(a), 7(a), and 9(a).

A needle-type $\left(\mathrm{Cu}_{x}, \mathrm{Ni}_{1-x}\right)_{6} \mathrm{Sn}_{5}$ IMC was observed in
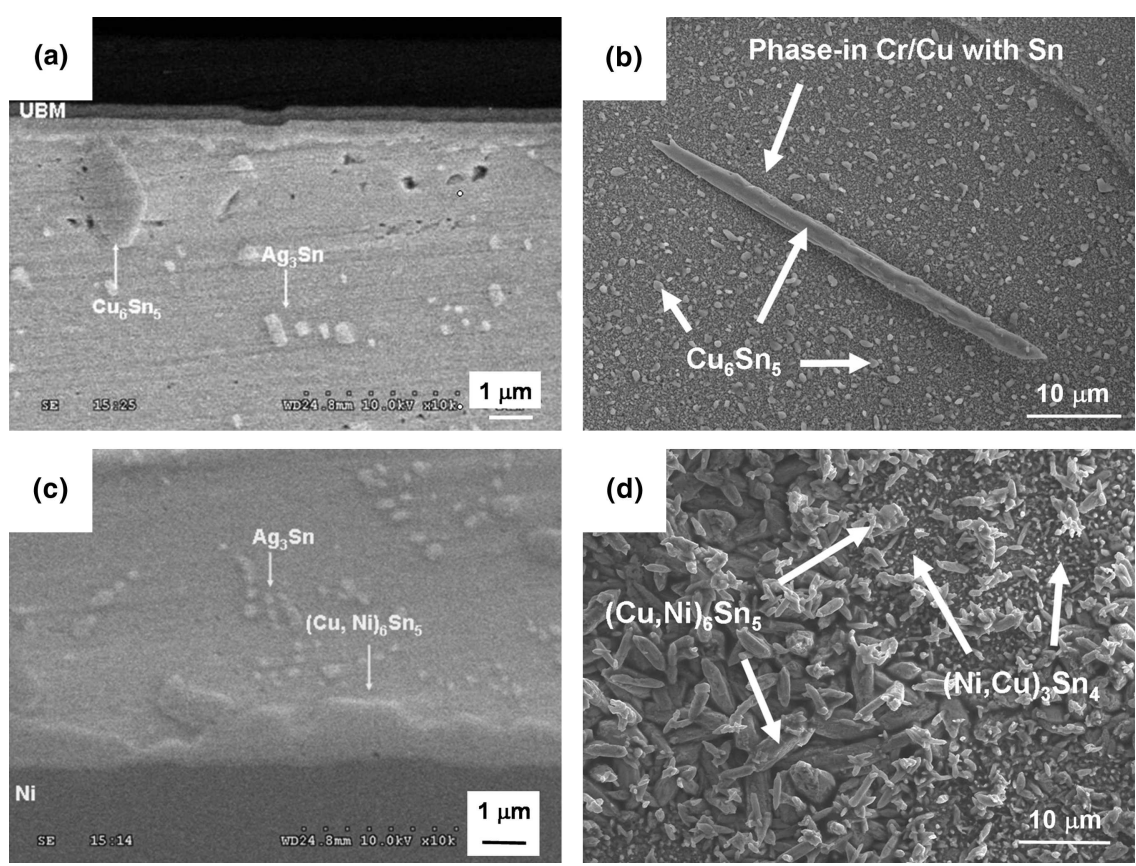

FIG. 9. SEM images of the interfacial microstructure of the eutectic SnAg3.8Cu0.7 solder bump in flip-chip package after the second reflow: (a) cross-sectional view of the chip side, (b) plan view of the chip side, (c) cross-sectional view of the substrate side, and (d) plan view of the substrate side. No cross interactions were found in this package. 
TABLE I(a). IMCs formed on the substrate side and their composition for bumped substrate and flip-chip package.

\begin{tabular}{|c|c|c|c|c|}
\hline \multirow[b]{2}{*}{ Solder } & \multicolumn{2}{|c|}{ Bumped substrate } & \multicolumn{2}{|c|}{ Flip-chip package } \\
\hline & IMCs & $\begin{array}{c}\text { Composition } \\
\text { (at.\%) }\end{array}$ & IMCs & $\begin{array}{c}\text { Composition } \\
\text { (at.\%) }\end{array}$ \\
\hline $\begin{array}{c}\text { Eutectic } \\
\mathrm{SnPb}\end{array}$ & $\mathrm{Ni}_{3} \mathrm{Sn}_{4}$ & $\begin{array}{l}\text { Ni: } 38 \pm 1 \\
\text { Sn: } 62 \pm 1\end{array}$ & $\begin{array}{l}\left(\mathrm{Cu}_{\mathrm{x}}, \mathrm{Ni}_{1-\mathrm{x}}\right)_{6} \mathrm{Sn}_{5} \\
\left(\mathrm{Ni}_{y}, \mathrm{Cu}_{1-y}\right)_{3} \mathrm{Sn}_{4}\end{array}$ & $\begin{array}{l}\text { Cu: } 47 \pm 4 \\
\text { Sn: } 39 \pm 1 \\
\text { Ni: } 14 \pm 2 \\
\text { Ni: } 32 \pm 3 \\
\text { Cu: } 13 \pm 4 \\
\text { Sn: } 55 \pm 2\end{array}$ \\
\hline SnAg3.5 & $\mathrm{Ni}_{3} \mathrm{Sn}_{4}$ & $\begin{array}{l}\text { Ni: } 43 \pm 1 \\
\text { Sn: } 57 \pm 1\end{array}$ & $\begin{array}{l}\left(\mathrm{Cu}_{x}, \mathrm{Ni}_{1-x}\right)_{6} \mathrm{Sn}_{5} \\
\left(\mathrm{Ni}_{y}, \mathrm{Cu}_{1-y}\right)_{3} \mathrm{Sn}_{4}\end{array}$ & $\begin{array}{l}\text { Ni: } 20 \pm 1 \\
\text { Cu: } 32 \pm 1 \\
\text { Sn: } 48 \pm 1 \\
\text { Ni: } 32 \pm 2 \\
\text { Cu: } 10 \pm 4 \\
\text { Sn: } 58 \pm 2\end{array}$ \\
\hline SnSb5 & $\mathrm{Ni}_{3} \mathrm{Sn}_{4}$ & $\begin{array}{l}\text { Ni: } 45 \pm 2 \\
\text { Sn: } 55 \pm 2\end{array}$ & $\begin{array}{l}\left(\mathrm{Cu}_{x}, \mathrm{Ni}_{1-x}\right)_{6} \mathrm{Sn} 5 \\
\left(\mathrm{Ni}_{y}, \mathrm{Cu}_{1-y}\right)_{3} \mathrm{Sn}_{4}\end{array}$ & $\begin{array}{l}\text { Ni: } 18 \pm 1 \\
\text { Cu: } 35 \pm 1 \\
\text { Sn: } 43 \pm 1 \\
\text { Ni: } 38 \pm 1 \\
\text { Cu: } 9 \pm 1 \\
\text { Sn: } 53 \pm 1\end{array}$ \\
\hline $\begin{array}{r}\text { SnAg3.8 } \\
\text { Cu0.7 }\end{array}$ & $\left(\mathrm{Ni}_{y}, \mathrm{Cu}_{1-y}\right)_{3} \mathrm{Sn}_{4}$ & $\begin{array}{l}\mathrm{Ni}: 30 \pm 1 \\
\mathrm{Cu}: 17 \pm 5 \\
\text { Sn: } 53 \pm 4\end{array}$ & $\begin{array}{l}\left(\mathrm{Cu}_{x}, \mathrm{Ni}_{1-x}\right)_{6} \mathrm{Sn}_{5} \\
\left(\mathrm{Ni}_{y}, \mathrm{Cu}_{1-y}\right)_{3} \mathrm{Sn}_{4}\end{array}$ & $\begin{array}{l}\text { Ni: } 17 \pm 4 \\
\text { Cu: } 44 \pm 7 \\
\text { Sn: } 39 \pm 4 \\
\text { Ni: } 38 \pm 2 \\
\text { Cu: } 8 \pm 1 \\
\text { Sn: } 54 \pm 2\end{array}$ \\
\hline
\end{tabular}

TABLE I(b). IMCs formed on the chip side and their composition for bumped die and flip-chip package.

\begin{tabular}{|c|c|c|c|c|}
\hline \multirow[b]{2}{*}{ Solder } & \multicolumn{2}{|c|}{ Bumped die } & \multicolumn{2}{|c|}{ Flip-chip package } \\
\hline & IMCs & $\begin{array}{l}\text { Composition } \\
\text { (at.\%) }\end{array}$ & IMCs & $\begin{array}{c}\text { Composition } \\
\text { (at.\%) }\end{array}$ \\
\hline Eutectic $\mathrm{SnPb}$ & $\mathrm{Cu}_{6} \mathrm{Sn}_{5}$ & $\begin{array}{l}\text { Sn: } 43 \pm 2 \\
\text { Cu: } 57 \pm 2\end{array}$ & $\mathrm{Cu}_{6} \mathrm{Sn}_{5}{ }^{\mathrm{a}}$ & $\begin{array}{l}\text { Au: } \quad 4 \pm 1 \\
\text { Cu: } 53 \pm 1 \\
\text { Sn: } 43 \pm 1\end{array}$ \\
\hline SnAg3.5 & $\mathrm{Cu}_{6} \mathrm{Sn}_{5}$ & $\begin{array}{l}\text { Sn: } 42 \pm 2 \\
\text { Cu: } 58 \pm 2\end{array}$ & $\left(\mathrm{Cu}_{x}, \mathrm{Ni}_{1-x}\right)_{6} \mathrm{Sn}_{5}$ & $\begin{array}{l}\text { Ni: } 21 \pm 1 \\
\text { Cu: } 37 \pm 1 \\
\text { Sn: } 42 \pm 1\end{array}$ \\
\hline SnSb5 & $\mathrm{Cu}_{6} \mathrm{Sn}_{5}$ & $\begin{array}{l}\text { Sn: } 44 \pm 4 \\
\text { Cu: } 56 \pm 4\end{array}$ & $\left(\mathrm{Cu}_{x}, \mathrm{Ni}_{1-x}\right)_{6} \mathrm{Sn}_{5}$ & $\begin{array}{c}\text { Ni: } 24 \pm 1 \\
\text { Cu: } 33 \pm 1 \\
\text { Sn: } 43 \pm 1\end{array}$ \\
\hline SnAg3.8Cu0.7 & $\mathrm{Cu}_{6} \mathrm{Sn}_{5}$ & $\begin{array}{c}\text { Sn: } 44 \pm 3 \\
\text { Cu: } 56 \pm 3\end{array}$ & $\mathrm{Cu}_{6} \mathrm{Sn}_{5}$ & $\begin{array}{l}\mathrm{Cu}: 61 \pm 1 \\
\mathrm{Sn}: 39 \pm 1\end{array}$ \\
\hline
\end{tabular}

${ }^{\mathrm{a}} \mathrm{Few}\left(\mathrm{Cu}_{x}, \mathrm{Ni}_{1-x}\right)_{6} \mathrm{Sn}_{5}$ IMCs were also found.

the $\mathrm{SnPb}$ solder. It was found that scallop-type $\mathrm{Cu}_{6} \mathrm{Sn}_{5}$ IMCs transformed into needle-type $\left(\mathrm{Cu}_{x}, \mathrm{Ni}_{1-x}\right)_{6} \mathrm{Sn}_{5}$ IMCs when $\mathrm{Ni}$ atoms dissolved in the $\mathrm{Cu}_{6} \mathrm{Sn}_{5}$ IMCs. ${ }^{19-22}$ In our system, similar reaction may take place. The $\mathrm{Ni}$ atoms from the substrate side may react with the $\mathrm{Cu}_{6} \mathrm{Sn}_{5}$ IMCs or $\mathrm{Cu}$ and $\mathrm{Sn}$ to form needle-type $\left(\mathrm{Cu}_{x} \mathrm{Ni}_{1-x}\right)_{6} \mathrm{Sn}_{5}$ IMCs.

Table I(b) tabulates the IMCs formed on the chip side and their compositions for the bumped die and the flip-chip package, which shows the IMC evolution in the interfaces of the four solders and the UBM after reflow. For $\mathrm{SnPb}$ solder, the small particles coated on the surface of $\mathrm{Cu}_{6} \mathrm{Sn}_{5}$ may be $\mathrm{AuSn}_{4}$ IMCs, since Kuo reported that the $\mathrm{AuSn}_{4}$ and $\mathrm{Cu}-\mathrm{Ni}-\mathrm{Sn}$ IMCs may have lower interfacial energy. ${ }^{18}$ Therefore, during the second reflow for joining the flip chip package, the Au layer dissolved very rapidly into the solder to form $\mathrm{AuSn}_{4} \mathrm{IMCs}^{16}$ Then they may diffuse to the chip side and deposit on the surface of $\mathrm{Cu}_{6} \mathrm{Sn}_{5}$.

However, it is interesting that the migration of Au does not occur in $\mathrm{Pb}$-free solder joints during their second reflow. Kao reported that the addition of Ni particles may inhibit the redistribution of $\mathrm{AuSn}_{4}$ IMCs during solid state aging. ${ }^{23} \mathrm{Tu}$ et al. also found that Au-Sn IMC deposited on the surface of $\mathrm{Cu}_{6} \mathrm{Sn}_{5}$ IMCs after reflow, ${ }^{10}$ and they reported that there was no $\mathrm{AuSn}_{4}$ redistribution observed in $\mathrm{Pb}$-free solder. ${ }^{9}$ Moreover, the solubility of $\mathrm{Ni}$ in the eutectic $\mathrm{SnPb}$ solder is estimated to be 0.052 at. \% at $220{ }^{\circ} \mathrm{C}$, but it is 0.28 at.\% in the eutectic SnAg solder at $250{ }^{\circ} \mathrm{C} .{ }^{24}$ Thus, it is inferred that the higher solubility of $\mathrm{Ni}$ in the molten $\mathrm{Pb}$-free solders may be able to stabilize the $\mathrm{AuSn}_{4}$ IMCs.

In addition, only few $\mathrm{Ni}$ atoms were detected on the chip side for eutectic $\mathrm{SnPb}$ solder, since the solubility of $\mathrm{Ni}$ in the eutectic $\mathrm{SnPb}$ solder is as low as 0.052 at.\% at $220{ }^{\circ} \mathrm{C}$. However, it reaches 0.28 at.\% in the eutectic SnAg solder at $250{ }^{\circ} \mathrm{C}$, which may be responsible for the higher Ni content in the IMCs on the chip side in the $\mathrm{Pb}$-free solder. For $\mathrm{SnSb}$ solder, although its Ni solubility is not available, it is speculated that the solubility of $\mathrm{Ni}$ is close to that in $\mathrm{SnAg}$ solder. It is worth noting that the IMCs on the chip side of the SnSb solder did not spall after the second reflow. Suraski et al. reported that $0.5 \%$ doping of antimony could slow down the copper dissolution rate during wave soldering. Thus, compared with that in $\mathrm{SnAg}$ and $\mathrm{SnAgCu}$ solders, the $\mathrm{Cu}$ consumption rate in SnSb solder may be slower. ${ }^{25}$ However, the reason for that is not clear at this moment, and thus more experimental data are needed to prove it.

Regarding the absence of $\mathrm{Ni}$ on the chip side for the $\mathrm{SnAgCu}$ solder after the second reflow, it is believed that the $\left(\mathrm{Cu}_{x} \mathrm{Ni}_{1-x}\right)_{6} \mathrm{Sn}_{5}$ IMCs may play an important role in inhibiting Ni diffusion. It is reported that the $\mathrm{Cu}$ solubility limit in pure $\mathrm{Sn}$ at $240{ }^{\circ} \mathrm{C}$ is about $1.1 \%$. Thus, it is inferred that, for the $\mathrm{SnAg} 3.8 \mathrm{Cu} 0.7$ solder, the $\mathrm{Cu}$ concentration in the bumped die may be higher than that in the other three solders. When the bumped die was reflowed on the substrate, the amount of $\left(\mathrm{Cu}_{x}, \mathrm{Ni}_{1-x}\right)_{6} \mathrm{Sn}_{5}$ IMCs in the solder was larger than that in the other three solders. These IMCs formed above $\left(\mathrm{Ni}_{y}, \mathrm{Cu}_{1-y}\right)_{3} \mathrm{Sn}_{4}$ IMCs on the substrate side. Since $\left(\mathrm{Cu}_{x}, \mathrm{Ni}_{1-x}\right)_{6} \mathrm{Sn}_{5}$ can dissolve as much as $26.7 \% \mathrm{Ni}$ atoms, it is inferred that once the $\mathrm{Ni}$ atoms dissolve into the solder, they are captured immediately by the ternary $\left(\mathrm{Cu}_{x}, \mathrm{Ni}_{1-x}\right)_{6} \mathrm{Sn}_{5}$ 
IMCs. ${ }^{26}$ Another possibility is that, when the $\mathrm{Cu}$ flux from the chip side meets the Ni atoms in the substrate, they form $\mathrm{Cu}-\mathrm{Ni}-\mathrm{Sn}$ ternary compounds right away. Since the $\mathrm{Cu}$ dissolution rate in solder is faster than that of $\mathrm{Ni}$ in solder, $\mathrm{Cu}$ atoms may diffuse to the substrate side before the $\mathrm{Ni}$ atoms reach the chip side. Liu et al. also reported that only binary $\mathrm{Cu}_{6} \mathrm{Sn}_{5}$ formed in the $\mathrm{Cu}$ end when eutectic SnAg solder was reflowed with $\mathrm{Cu}$ and $\mathrm{Ni}$ foils up to $20 \mathrm{~min}$, while $\left(\mathrm{Cu}_{x,} \mathrm{Ni}_{1-x}\right)_{6} \mathrm{Sn}_{5}$ was found in the Ni end. ${ }^{11}$ Nickel atoms did not diffuse to the $\mathrm{Cu}$ foil side after even 20-min reflow, which contradicts to our $\mathrm{SnAg}$ results. The discrepancy may be attributed to the following reason. The metallization layers they used were $\mathrm{Cu}$ and $\mathrm{Ni}$ foils, which had unlimited supply of $\mathrm{Cu}$ and $\mathrm{Ni}$ atoms. Therefore, on the $\mathrm{Ni}$ foil side, there existed a continuous flux of $\mathrm{Cu}$ atoms from the $\mathrm{Cu}$ foil side, and the $\mathrm{Cu}$ atoms reacted with the $\mathrm{Ni}$ and $\mathrm{Sn}$ atoms to form $\left(\mathrm{Cu}_{x}, \mathrm{Ni}_{1-x}\right)_{6} \mathrm{Sn}_{5}$ IMC. Therefore, the thickness of the $\left(\mathrm{Cu}_{x}, \mathrm{Ni}_{1-x}\right)_{6} \mathrm{Sn}_{5}$ layer increased with the increase of reflowing time. Nevertheless, in our SnAg case, the flux of $\mathrm{Cu}$ atoms was limited due to the thin film UBM structure. When the $\mathrm{Cu}$ layer was depleted, the $\mathrm{Ni}$ atoms on the substrate side may be able to diffuse to the chip side.

\section{CONCLUSIONS}

Cross interactions on the formation of IMCs have been found in eutectic $\mathrm{SnPb}, \mathrm{SnAg} 3.5, \mathrm{SnAg} 3.8 \mathrm{Cu} 0.7$, and SnSb5 solders joined to $\mathrm{Cu} / \mathrm{Cr}-\mathrm{Cu} / \mathrm{Ti}$ on the chip side and $\mathrm{Au} / \mathrm{Ni}$ metallization on the substrate side. For all the three $\mathrm{Pb}$-free solders, $\mathrm{Cu}$ atoms on the chip side diffused to the substrate side during reflow to form $\left(\mathrm{Cu}_{x}, \mathrm{Ni}_{1-x}\right)_{6} \mathrm{Sn}_{5}$ and $\left(\mathrm{Ni}_{y}, \mathrm{Cu}_{1-y}\right)_{3} \mathrm{Sn}_{4}$, while only $\left(\mathrm{Cu}_{x} \mathrm{Ni}_{1-x}\right)_{6} \mathrm{Sn}_{5}$ IMCs were observed for the $\mathrm{SnPb}$ solder. A concentration gradient and chemical potential gradient are considered to be responsible for the $\mathrm{Cu}$ diffusion. Au atoms on the substrate side were detected on the surface of $\mathrm{Cu}_{6} \mathrm{Sn}_{5}$ IMCs on the chip side after the second reflow, and only few Ni atoms were detected on the chip side in the $\mathrm{SnPb}$ solder. In addition, the $\mathrm{Ni}$ atoms on the substrate side diffused to the chip side during the second reflow to form ternary $\left(\mathrm{Cu}_{x}, \mathrm{Ni}_{1-x}\right)_{6} \mathrm{Sn}_{5}$ IMCs in the SnAg3.5 and SnSb5 solders. The chemical potential gradient due to lower free energy of the ternary IMCs were proposed to account for the diffusion of $\mathrm{Ni}$ flux from the substrate side to the chip side.

\section{ACKNOWLEDGMENTS}

The authors would like to thank the National Science Council of the Republic of China for the financial support of this study through Grant No. 90-2216-E-009-042, and Professor C.Y. Liu at National Central University, Taiwan for helpful discussion.

\section{REFERENCES}

1. L.F. Miller: Controlled collapse reflow chip joining. IBM J. Res. Develop. 13, 239 (1969).

2. P.A. Totta and R.P. Sopher: SLT device metallurgy and its monolithic extensions. IBM J. Res. Develop. 13, 226 (1969).

3. K.N. Tu and K. Zeng: $\mathrm{Sn}-\mathrm{Pb}$ solder reaction in flip chip technology. Mater. Sci. Eng. Rep. R 34, 1 (2001).

4. D.R. Frear, J.W. Jang, J.K. Lin, and C. Zhang: Pb-free solders for flip-chip interconnects. JOM 53, 28 (2001).

5. K. Seelig and D. Suraski: The status of lead-free solders, in LeadFree Soldering Technology, edited by IEEE Components, Packaging, and Manufacturing Technology Society (Proc. of the 50th Electronic Components and Technology Conference, Las Vegas, NV, 2000) p. 1405.

6. H.K. Kim, H.K. Liou, and K.N. Tu: Three-dimensional morphology of a very rough interface formed in the soldering reaction between eutectic $\mathrm{SnPb}$ and $\mathrm{Cu}$. Appl. Phys. Lett. 66, 2337 (1995).

7. P.G. Kim, J.W. Jang, T.Y. Lee, and K.N. Tu: Interfacial reaction and wetting behavior in eutectic $\mathrm{SnPb}$ solder on $\mathrm{Ni} / \mathrm{Ti}$ thin films and Ni foils. J. Appl. Phys. 86, 6746 (1999).

8. C.E. Ho, Y.M. Chen, and C.R. Kao: Reaction kinetics of solderballs with pads in BGA packages during reflow soldering. J. Electron. Mater. 28, 1231 (1999).

9. K. Zeng and K.N. Tu: Six cases of reliability study of Pb-free solder joints in electronic packaging technology. Mater. Sci. Eng. Rep. $R$ 38, 55 (2002).

10. A.A. Liu, H.K. Kim, K.N. Tu, and P.A. Totta: Spalling of $\mathrm{Cu}_{6} \mathrm{Sn}_{5}$ spheroids in the solder reaction of eutectic $\mathrm{SnPb}$ on $\mathrm{Cr} / \mathrm{Cu} / \mathrm{Au}$ thin films. J. Appl. Phys. 80, 2774 (1996).

11. C.Y. Liu and S.J. Wang: Prevention of spalling by the self-formed reaction barrier layer on controlled collapse chip connections under bump metallization. J. Electron. Mater. 32, 1303 (2003).

12. C.Y. Liu and S.J. Wang: Study of interaction between $\mathrm{Sn}-\mathrm{Cu}$ and $\mathrm{Sn}-\mathrm{Ni}$ interfacial reaction by using a $\mathrm{Cu} / \mathrm{Sn} 3.5 \mathrm{Ag} / \mathrm{Ni}$ sandwich structure. J. Electron. Mater. 32, 1303 (2003).

13. F. Zhang, M. Li, C.C. Chum, and C-H. Tung: Effects of substrate metallizations on solder/underbump metallization interfacial reactions in flip-chip packages during thermal aging. J. Mater. Res. 18, 1333 (2003).

14. S.C. Cheng and K.L. Lin: Interfacial evolution between $\mathrm{Cu}$ and $\mathrm{Pb}$-free $\mathrm{Sn}-\mathrm{Zn}-\mathrm{Ag}-\mathrm{Al}$ solders upon aging at $150{ }^{\circ} \mathrm{C}$. J. Mater. Res. 18, 1795 (2003).

15. J.W. Jang, P.G. Kim, K.N. Tu, D. Frear, and P. Thompson: Solder reaction-assisted crystallization of electroless Ni (P) under-bump metallization in low cost flip chip technology. J. Appl. Phys. 85, 8456 (1999).

16. P.G. Kim and K.N. Tu: Morphology of wetting reaction of eutectic $\mathrm{SnPb}$ solder on Au foils. J. Appl. Phys. 80, 3822 (1996).

17. D.A. Porter and K.E. Easterling: Phase Transformations in Metals and Alloys, 2nd ed. (Chapman and Hall, London, U.K., 1992), pp. $77-80$.

18. W.T. Chen, C.E. Ho, and C.R. Kao: Effect of $\mathrm{Cu}$ concentration on the interfacial reactions between $\mathrm{Ni}$ and $\mathrm{Sn}-\mathrm{Cu}$ solders. J. Mater. Res. 17, 263 (2002).

19. C.E. Ho, Y.L. Lin, and C.R. Kao: Strong effect of $\mathrm{Cu}$ concentration on the reaction between lead-free microelectronic solders and Ni. Chem. Mater. 14, 949 (2002).

20. S.W. Chen, S.H. Wu, and S.W. Lee: Interfacial reactions in the $\mathrm{Sn}-(\mathrm{Cu}) / \mathrm{Ni}, \mathrm{Sn}-(\mathrm{Ni}) / \mathrm{Cu}$, and $\mathrm{Sn} /(\mathrm{Cu}, \mathrm{Ni})$ systems. J. Electron. Mater. 32, 1188 (2003). 
21. M.O. Alam, Y.C. Chan, and K.N. Tu: Effect of $0.5 \mathrm{wt} \% \mathrm{Cu}$ in $\mathrm{Sn}-3.5 \% \mathrm{Ag}$ solder on the interfacial reaction with $\mathrm{Au} / \mathrm{Ni}$ metallization. Chem. Mater. 15, 4340 (2003).

22. T.M. Korhonen, P. Su, S.J. Hong, M.A. Korhonen, and C.Y. Li: Reaction of lead-free solders with CuNi metallization. J. Electron. Mater. 29, 1194 (2000).

23. C.E. Ho, L.C. Shiau, and C.R. Kao: Inhibiting the formation of $\left(\mathrm{Au}_{1-\mathrm{x}} \mathrm{Ni}_{\mathrm{x}}\right) \mathrm{Sn}_{4}$ and reducing the consumption of Ni metallization in solder joints. J. Electron. Mater. 31, 1264 (2002).
24. K. Zeng and J. Kivilahti: Thermodynamic calculation of saturation solubilities of some metals in Pb-free solders. Internal Report (Helsinki University of Technology, Helsinki, Finland, 2000.)

25. D. Suraski and K. Seelig: Controlling copper build up in automatic soldering equipment using lead-free solder, http://www. aimsolder.com.au/lead free.htm.

26. C.H. Lin, S.W. Chen, and C.H. Wang: Phase equilibria and solidification properties of Sn-Cu-Ni alloys. J. Electron. Mater. 31, 907 (2002). 